\title{
Grid Connected PV System Using ANFIS Based MPPT Controller in Real Time
}

\author{
Muhammed Y. Worku ${ }^{1}$ and M.A. Abido ${ }^{2}$ \\ ${ }^{1}$ King Fahd University of Petroleum and Minerals \\ Research Institute, Center for Engineering Research \\ Dhahran, Saudi Arabia \\ Tel: +966-559713973, Fax: +966-138603535, email: muhammedw@kfupm.edu.sa \\ ${ }^{2}$ King Fahd University of Petroleum and Minerals \\ Department of Electrical Engineering \\ Dhahran, Saudi Arabia \\ email: mabido@kfupm.edu.sa
}

\begin{abstract}
This paper presents an efficient design and real time implementation of a complete model and control of grid connected photovoltaic (PV) array. To capture the maximum available solar power, Adaptive Neuro-Fuzzy Inference System (ANFIS) implemented in real time using dSPACE is proposed. An efficient and independent active and reactive P-Q power control is proposed and implemented to transfer the generated power to the grid using a voltage source converter (VSC). The proposed controllers are implemented along with the PV system considered in Real Time Digital Simulator (RTDS) and dSPACE 1104 controller to evaluate their effectiveness. By varying the irradiation and temperature, the effectiveness of the proposed P$\mathrm{Q}$ controller to transfer the generated power to the grid is examined. It is observed that the hardware in the loop results verify the superiority of the proposed approach.
\end{abstract}

\section{Key words}

PV system, Active and reactive power control, ANFIS MPPT, Voltage source converter, RTDS

\section{Introduction}

As a result of increasing environmental concern, price volatility and carbon impact of fossil fuels, the development of renewable energy based Distributed Generation (DG) is moving fast to meet the worldwide urgent needs of utilizing clean energy sources and minimizing costs. Solar energy is among the promising renewable energy sources and photovoltaic (PV) system provides the most direct method to convert solar energy into electrical energy without environmental contamination. The power generated from the PV system can be used in island or grid connected modes [1]. The generated DC power from the PV system is transferred to the grid using a voltage source converter (VSC). The output power from the PV array is dependent on inputs irradiation and temperature which vary throughout the day. There is always one point that gives the maximum power from the PV array depending on these variations. Different maximum power point tracking (MPPT) design methods including Perturb and observe (P\&O), Incremental Conductance (IC), artificial intelligence techniques such as Artificial Neural Networks (ANNs) and Fuzzy Logic control have been reported in the literature to locate the best operating point [2]-[7].

The fuzzy-inference system (FIS) based MPPT has been proposed in [8]-[10]. Integrating FIS with ANN results in a powerful Artificial Intelligence technique known as Adaptive Network-Based Fuzzy Inference System (ANFIS) [11]-[12]. To build ANFIS-based MPPT controller, gathering a large amount of training data is the major challenge. Actual field data collected for training ANFIS-based MPPT has better performance than the conventional methods [13]. However, several problems are associated with the practical data. These include; it does not cover a wide dynamic range; only appropriate for a particular geographical location; and a time consuming task as large amount of data is required for better performance of ANFIS. Easy and fast way of getting training data is by simulation of PV model [14][15]. However, the effectiveness and accuracy of the PV model used to generate training data is crucial. This point has not been addressed to verify the competency of the training data and the MPPT controller.

The maximum power tracked by the MPPT can be used to supply a DC load or can be transferred to the grid using a VSC. A P-Q controller is used on the VSC to control the active and reactive power independently. While varying the irradiation and temperature, the P-Q controller directly transfers the generated power to the grid.

In this paper, an independent active and reactive power controller is proposed and implemented to transfer the generated power from the PV array to the grid. MPPT controller based on Adaptive Neuro-Fuzzy Inference System (ANFIS) is proposed and implemented to track 
the maximum power under varying irradiation and temperature. The generated PV power is integrated to the grid using two stage topology using buck converter and VSC. The duty cycle of the buck converter is controlled to track the maximum power using a PI controller. The inputs of the PI controller are the PV array output voltage and the output voltage of the ANFIS. The proposed efficient ANFIS-based MPPT controller takes accurate input-output data set used for the training of the controller gathered from the simulation studies using the developed PV model. For simplicity of the proposed MPPT controller, the inputs used are irradiation and temperature which can be directly measured. The implemented P-Q vector control adjusts independently the active and reactive power for grid integration. Real Time Digital Simulator (RTDS) and dSPACE controller are used for experimental implementation and verification of the whole system. The rest of the paper is organized as follows. Section II presents the system considered and PV modeling. The proposed controller is described in Section III. Hardware implementation is discussed in Section IV. Section V presents the results and discussions while Section VI presents the conclusion.

\section{System Modeling}

Two stage topology of grid connected PV system using buck converter and VSC is depicted in Fig. 1. To generate the required power from the PV system a number of series and parallel connected modules are used. The buck converter together with a PI controller is used to implement the MPPT. It also conditions the generated DC power to make it suitable for the inverter. The inverter converts the DC power to AC for grid integration. The duty cycle of the buck converter and the firing pulses of the inverter are continuously controlled. From Fig.1, $I_{P V}$, $V_{P V}$ and $P_{P V}$ represent the current, voltage and power generated from the PV array respectively, $I_{D C}$ and $V_{D C}$ are the DC link current and voltage respectively. $I, V_{g}$ and $P_{g}$ are the grid current, grid voltage and power delivered to the grid respectively where as $T$ is the coupling transformer. The details of the PV array model used in this paper can be found in [16].

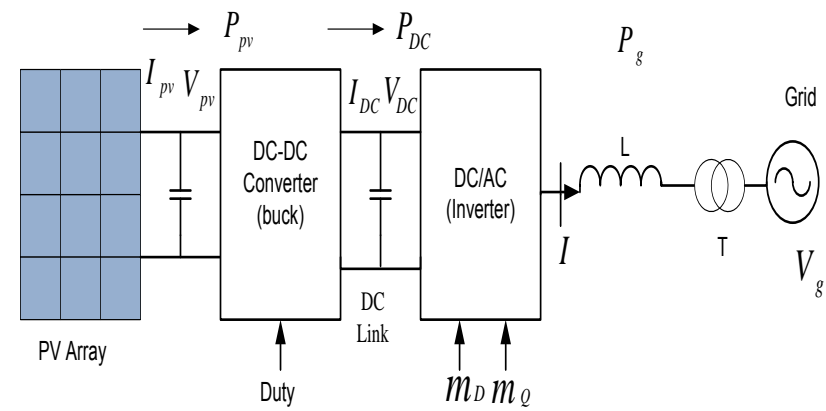

Fig.1. Grid connected PV system

\section{Proposed Controller}

Two independent controllers are proposed for the buck converter and the VSC. The duty cycle of the buck converter is continuously adjusted under varying irradiation and temperature to track the maximum available power using ANFIS based MPPT. A P-Q control is implemented for the VSC to transfer the generated power to the grid. The proposed controllers are explained in the subsequent sections.

\section{A. ANFIS Based MPPT Controller}

Like neural networks, ANFIS has also network type structure and maps the input-output data set using the parameters of fuzzy membership functions. An ANFIS architecture based on the two-rule Sugeno system with two inputs, $\mathrm{x}$ and $\mathrm{y}$, and single output, $\mathrm{f}$ is used. Among the various learning methods, the hybrid learning algorithm that employs back propagation (BP) and least square estimation (LSE) to optimize the premise and consequent parameters is employed in this paper. To design a MPPT controller using ANFIS, first task is to gather the input-output data set for training purpose. This training data is generated using the developed PV model in RSCAD (interface software for the RTDS). A step-bystep process of data generation is illustrated in the flowchart shown in Fig. 2. As a first step, values of the five unknown parameters for the considered PV panel and PV array are estimated using an efficient algorithm (Differential Evolution is used). The training parameters are;

$N_{M A X}$ : Number of training data points, $T_{M I N}$ : Minimum temperature, $T_{M A X}$ : Maximum temperature, $S_{M I N}$ : Minimum Irradiation, $S_{M A X}$ : Maximum Irradiation.

Input of the proposed ANFIS-based MPPT controller is the ambient conditions, which are irradiation and temperature and its output is the reference voltage, $V_{r e f}$, as shown in Fig.3. The error of the actual PV voltage $V_{P V}$ and the reference voltage from the ANFIS MPPT $V_{\text {ref }}$ is processed by the PI regulator to generate the duty cycle for the buck converter. The DC link voltage $V_{D C}$, which is stored in the DC link capacitor $C_{D C}$, is the Duty multiplied by the PV array output voltage, $V_{P V}$.

$$
\text { Duty }=\left(V_{r e f}-V_{P V}\right) *\left(k_{P}+\frac{k_{I}}{s}\right)
$$

Where, $k_{P}$ and $k_{I}$ are the proportional and integral constants of the buck converter.

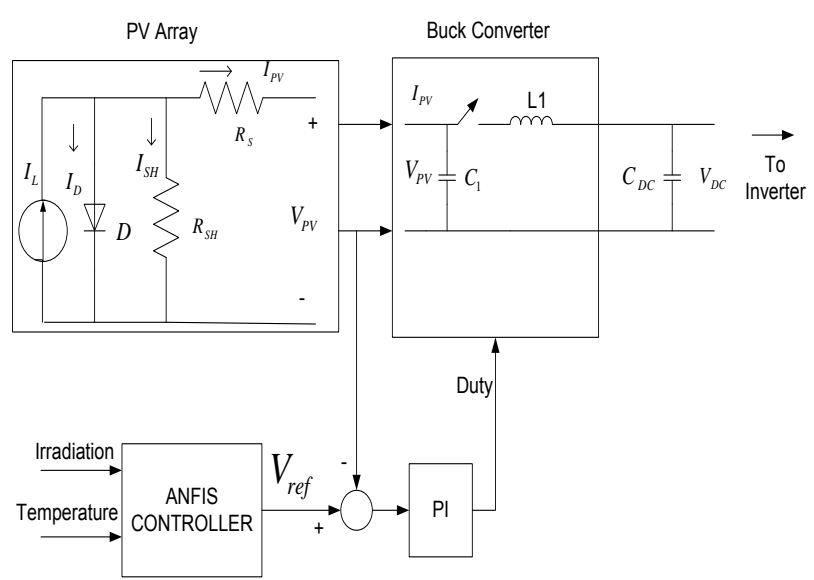

Fig.3. ANFIS based MPPT and DC-DC converter controller 


\section{B. $P-Q$ Controller for the Inverter}

Voltage source converter is used to transfer the generated PV power to the grid. An independent active and reactive power control using synchronously rotating reference frame is implemented for this converter. In the current control technique, the active current component $I_{D}$ controls the active power and reactive power flow is regulated by controlling $I_{Q}$. Controlling the magnitude and angle of the inverter output voltage in $D-Q$ frame controls independently the reactive and active power respectively. The inverter controller keeps the DC voltage constant for real power delivery to the grid. The reference input power to the DC link is the output power from the PV array. A phase locked loop (PLL) [17] is implemented to track the grid frequency $(\omega=2 \pi f)$ and phase angle $\theta$ that will be used for $\mathrm{ABC}$ to $\mathrm{DQ}$ conversion.

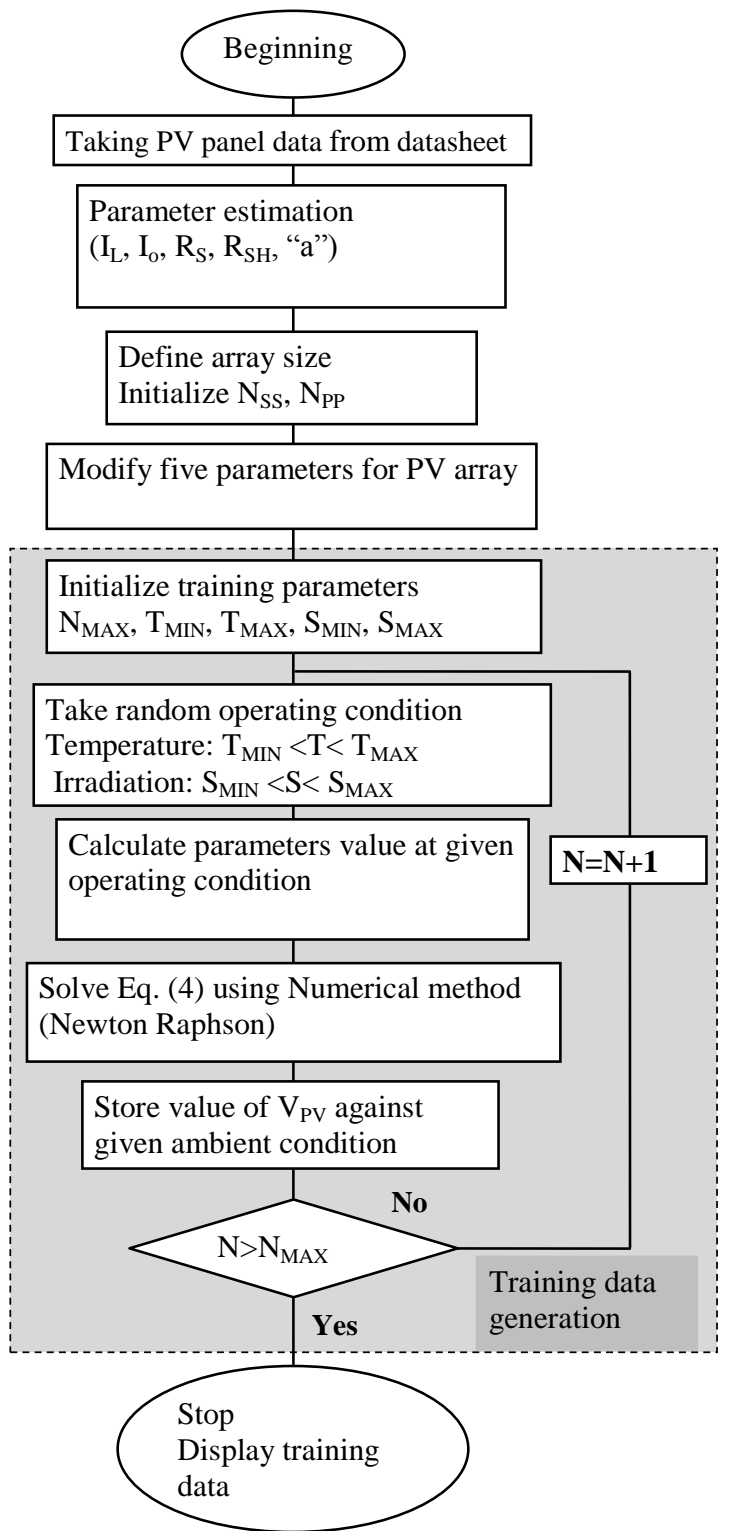

Fig.2. Proposed method to generate input output data set for ANFIS training

The VSC controller is shown in Fig.5. For unity power factor, the reference $Q$-axis current is kept 0 . Crosscoupling term and a feed forward voltage are used to improve the performance of the PI current controllers.
The $D$-axis outer voltage loop controller in the Laplace domain is:

$$
I_{D R E F}=\left(k_{P 1 D}+\frac{k_{I 1 D}}{s}\right) *\left(V_{D C}-V_{D C R E F}\right)
$$

The inner loop current controller will be:

$$
V_{D R E F}=\left(k_{P 2 D}+\frac{k_{I 2 D}}{s}\right) *\left(I_{D R E F}-I_{D}\right)
$$

Similarly, the $Q$-axis current controller in Laplace domain is given by:

$$
V_{Q R E F}=\left(k_{P 2 Q}+\frac{k_{I 2 Q}}{s}\right) *\left(0-I_{Q}\right)
$$

The control signals $\mathrm{mD}$ and $\mathrm{mQ}$ are then given by:

$$
\begin{gathered}
m_{D}=V_{D R E F}-w L I_{Q}+V_{L D} \\
m_{Q}=V_{Q R E F}+w L I_{D}+V_{L Q}
\end{gathered}
$$

Where, $k_{P}$ 's are the proportional gains and $k_{I}$ 's are the integral gains given in Table I.

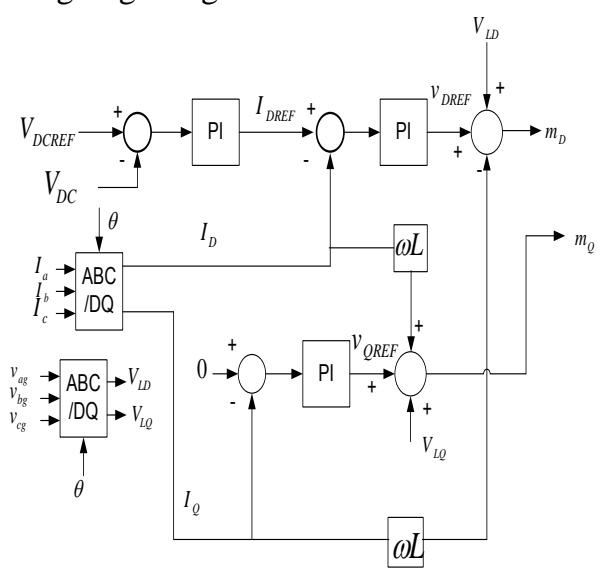

Fig.4. Decoupled inverter control

Table I: Values of PI parameters

\begin{tabular}{|l|l|}
\hline Parameter & Value \\
\hline For the inverter \\
\hline$k_{P 1 D}$ & 0.7 \\
\hline $\mathrm{K}_{\mathrm{I} 1 \mathrm{D}}$ & 0.2 \\
\hline $\mathrm{k}_{\mathrm{P} 2 \mathrm{D}}$ & 0.5 \\
\hline $\mathrm{K}_{\mathrm{I} 2 \mathrm{D}}$ & 15 \\
\hline $\mathrm{k}_{\mathrm{P} 2 \mathrm{Q}}$ & 5 \\
\hline $\mathrm{K}_{\mathrm{I} 2 \mathrm{Q}}$ & 0.5 \\
\hline For the DC-DC buck converter(MPPT) \\
\hline $\mathrm{K}_{\mathrm{P}}$ & 0.6 \\
\hline $\mathrm{K}_{\mathrm{I}}$ & 0.2 \\
\hline
\end{tabular}

\section{Hardware Implementation}

The proposed P-Q controller shown in Fig.4 is implemented in Real Time Digital Simulator (RTDS) and the ANFIS based MPPT controller designed is implemented in real domain using dSPACE DS1104 shown in Fig.5. Inputs to the proposed MPPT controller are irradiation and temperature and these are represented by DS1104ADC_C5 and DS1104ADC_C6 blocks in real time simulink model, respectively. These blocks are obtained from a dSPACE library in Matlab/Simulink and convert the analog signal to digital signal. Similarly the 
output of the proposed controller is Vref and represented by DA1104DAC_C1 and converts the digital signal to analog (DAC). Basically these blocks are used to integrate the dSPACE controller with external analog signals and devices. In our case these blocks are linked to GTAO and GTAI of the RTDS. DS1104ADC_C5 and DS1104ADC_C6 blocks are linked with the GTAO and accept the analog signals of temperature and irradiation as input. In the same way, DA1104DAC_C1 is linked with GTAI of RTDS and sends the control signal back to RTDS. The RTDS used is one Rack having three PB5 Processors, two GTnet cards and one GTWIF card. The complete experimental set up that includes the RTDS, dSPACE and the host PC containing the RSCAD interface software is shown in Fig. 6. Fig. 7 shows the closed loop control system between these components.

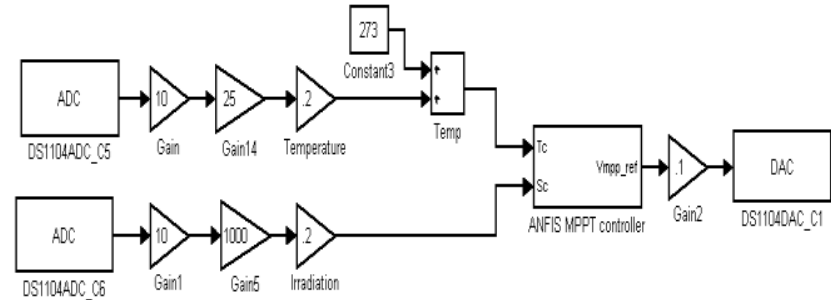

Fig.5. ANFIS based MPPT in Matlab/Simulink to be built in dSPACE

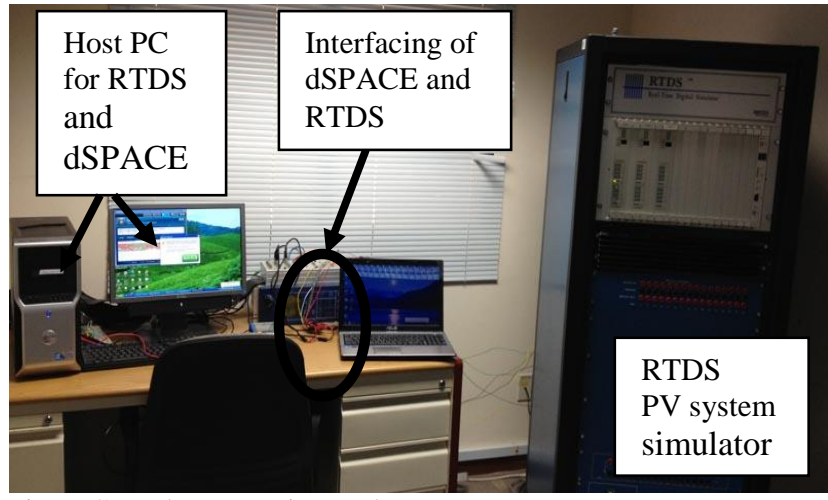

Fig.6. Complete experimental setup

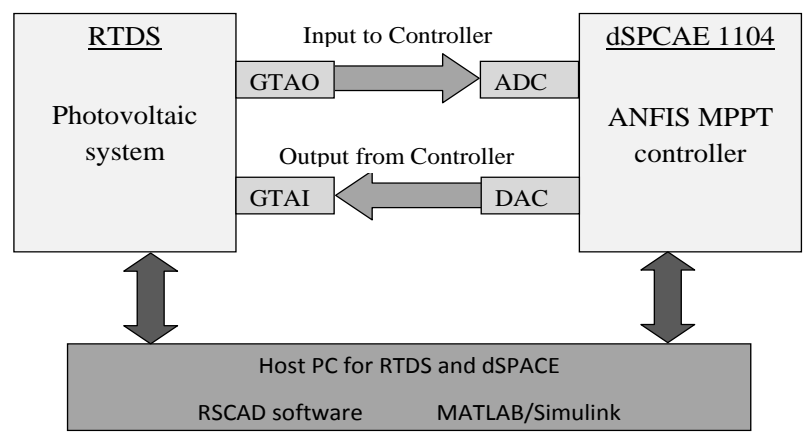

Fig.7. Closed loop control system

\section{Results and Discussions}

Fig.8 shows the complete RTDS model of the grid connected PV system used in this paper. A PV array with the specification given in Table II is developed. It consists of 50 series and 20 parallel connected modules. For the reference solar intensity of $1000 \mathrm{~W} / \mathrm{m}^{2}$ and $25^{\circ} \mathrm{c}$, the operating voltage $V_{P V}$ and current $I_{P V}$ at the MPPT will be
$50 \times 17.4 V=870 \mathrm{~V}$, and $20 \times 3.05 A=61 A$, respectively. The expected maximum output power at this operating point from this PV array is $53 \mathrm{~kW}(870 \mathrm{~V} \times 61 \mathrm{~A})$. To demonstrate the effectiveness of the proposed ANFIS based MPPT and grid connected PV system, the input irradiation profile shown in Fig. 9 is applied.

The response of the system for the applied disturbance is shown from Figs 10-13. The proposed MPPT controller tracks the maximum voltage from the PV array and maximum power $P_{P V}$ is generated. As depicted in Fig.10, the PV array generated the maximum power $P_{P V}$ by following the input irradiation profile. The inverter controller transfers this generated power directly to the grid $P_{g}$. Fig. 11 shows the output of the ANFIS based MPPT controller output voltage $V_{\text {ref }}$ and shows how the buck converter controller forces the PV array to track at a maximum PV array voltage $V_{P V}$. The DC link voltage is kept constant by the inverter controller with a reference $650 \mathrm{~V}$ as shown in Fig.12. The duty of the buck converter is continuously adjusted under varying irradiation as presented in Fig.13.

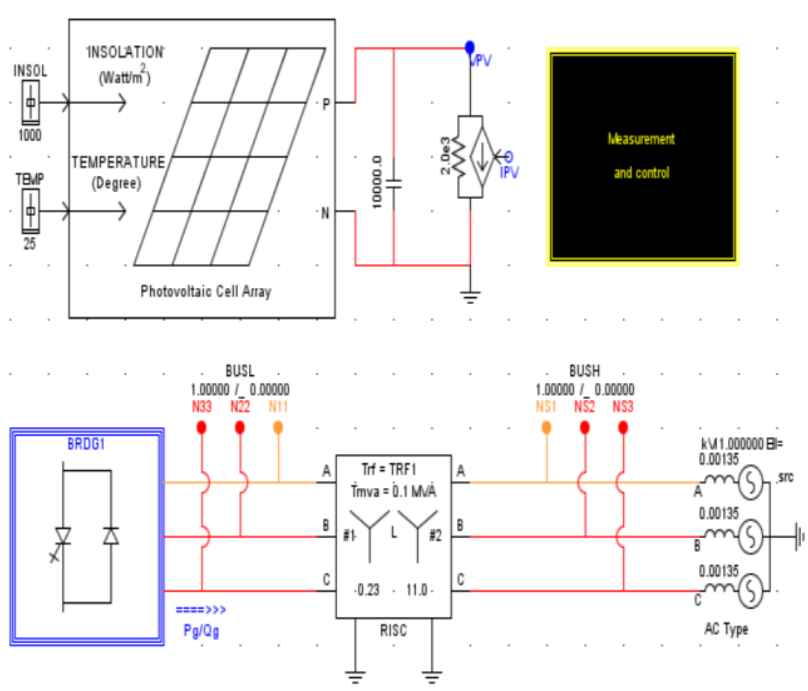

Fig.8. RTDS model of grid connected PV system

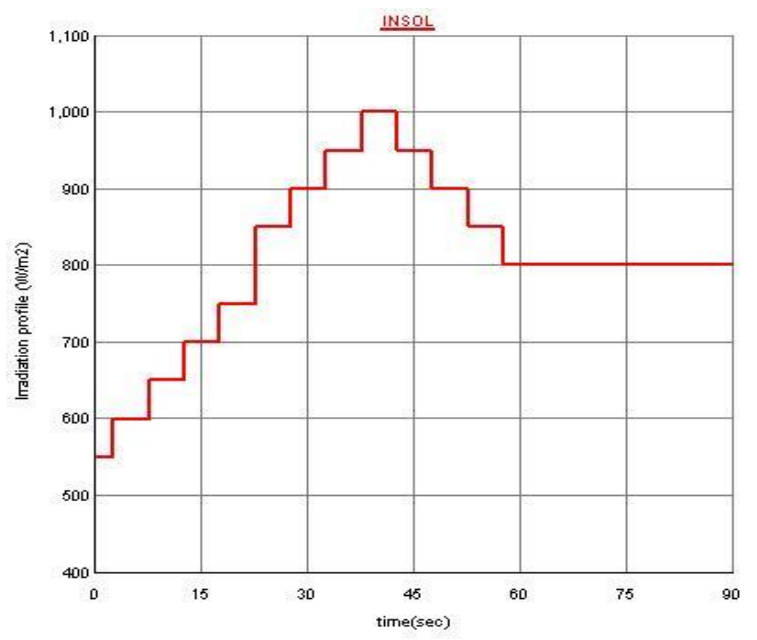

Fig.9. Irradiation profile input to the PV array 


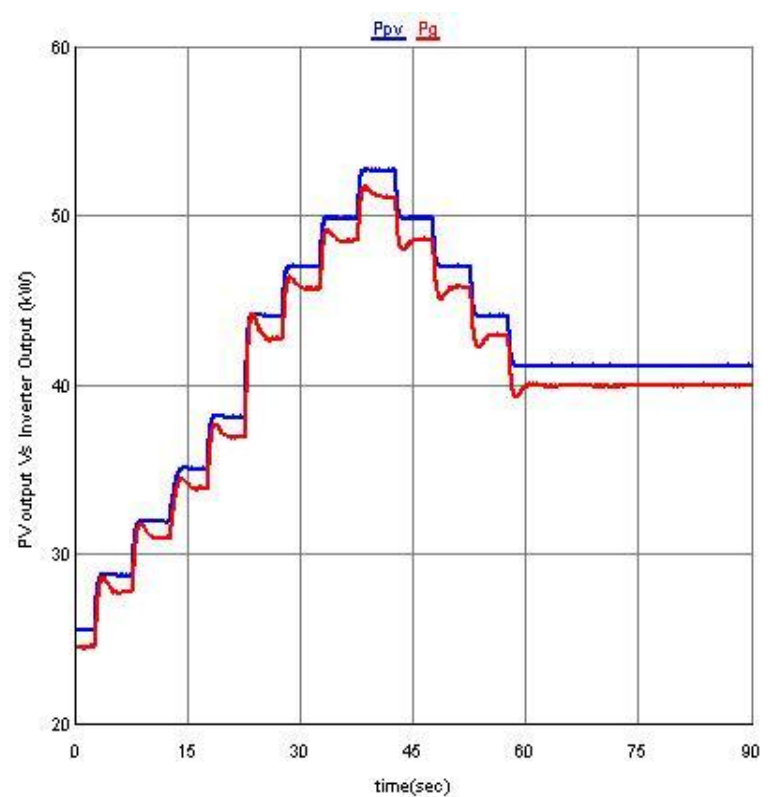

Fig.10. PV array output power $P_{P V}$ and inverter output power $P_{g}$

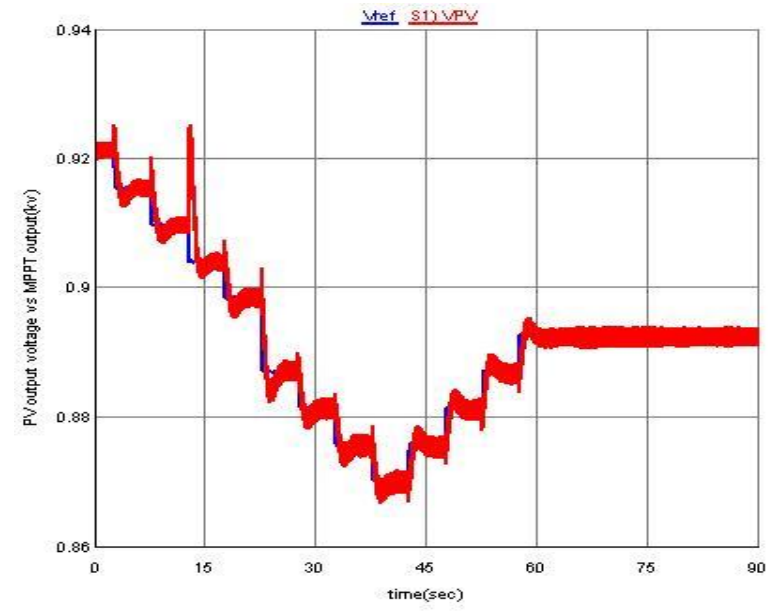

Fig.11. PV array output voltage $V_{P V}$ and MPPT output voltage $V_{\text {ref }}$
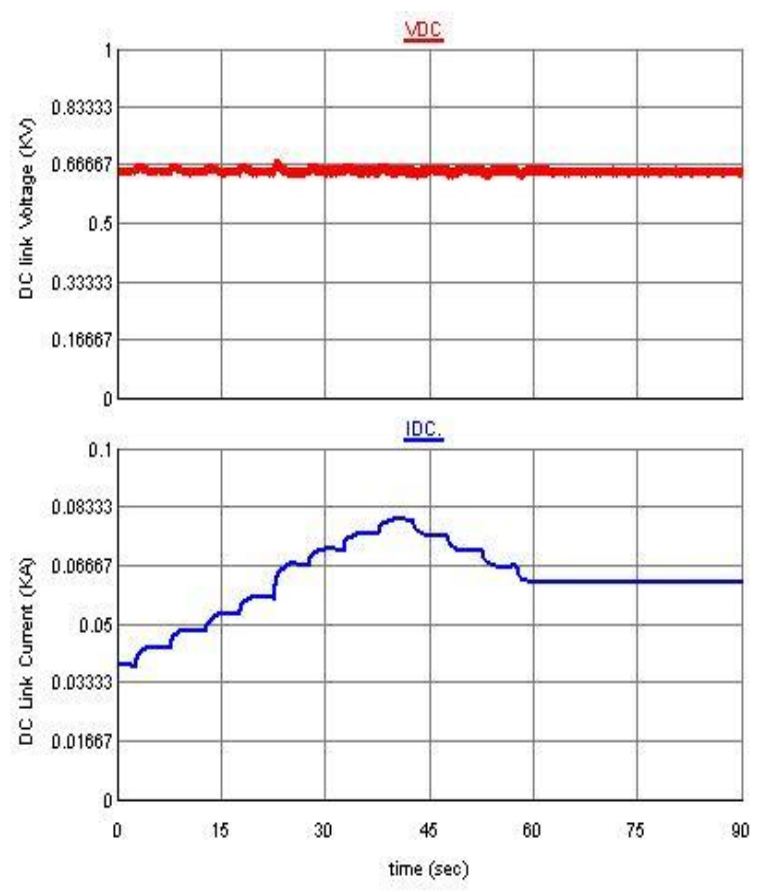

Fig.12. DC link voltage $V_{D C}$ and current $I_{D C}$

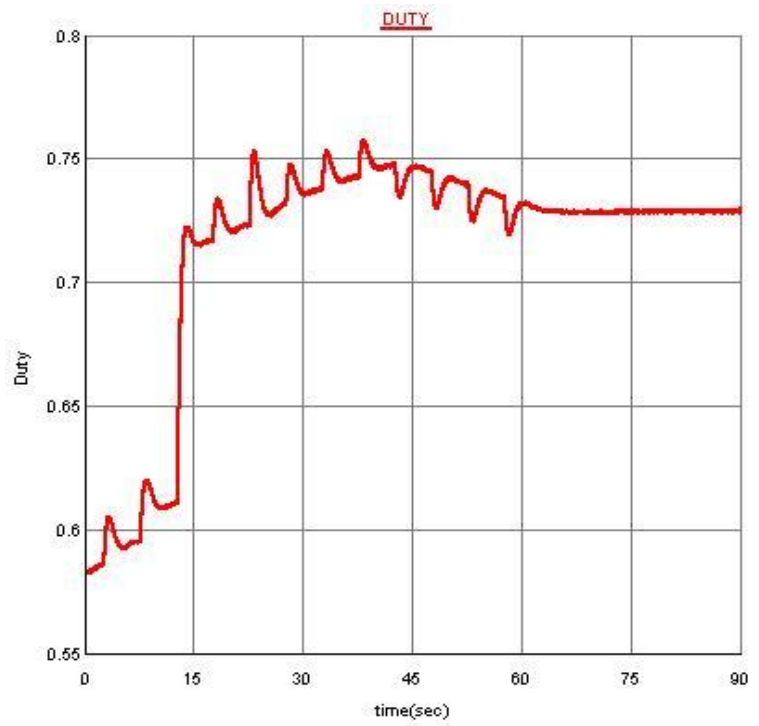

Fig.13. Duty cycle of the buck converter

\section{Conclusion}

This paper presented real time simulation of grid connected PV system with efficient P-Q and neuro-fuzzy controller. An independent active and reactive P-Q controller is implemented to transfer the generated power from the PV array to the grid. The proposed ANFISbased MPPT controller implemented in dSPACE is trained to force the PV array to work at the maximum power point. The trained controller has been experimentally implemented in dSPACE. The generated DC power is connected to the grid using a voltage source converter. A vector controller is implemented in RTDS to control independently the active and reactive power. RTDS and dSPACE are used to assess the validity of the proposed controllers. Results show that the proposed 
controllers are efficient in delivering the maximum power from the PV to the grid.

Table II: PV panel Parameter

\begin{tabular}{|l|c|}
\hline Parameter & Value \\
\hline Open Circuit Voltage & $21.7 \mathrm{~V}$ \\
\hline Short circuit current & $3.35 \mathrm{~A}$ \\
\hline Voltage at $\mathrm{P}_{\mathrm{MAX}}$ & $17.4 \mathrm{~V}$ \\
\hline Current at $\mathrm{P}_{\mathrm{MAX}}$ & $3.05 \mathrm{~A}$ \\
\hline Series connected modules $\left(\mathrm{N}_{\mathrm{SS}}\right)$ & 50 \\
\hline Parallel connected modules $\left(\mathrm{N}_{\mathrm{PP}}\right)$ & 20 \\
\hline Number of PV cells in each model & 36 \\
\hline Ideality factor of PV diode, $a$ & 1.5 \\
\hline Temperature Dependancy factor & 3 \\
\hline Reference Temperature & $25{ }^{\circ} \mathrm{c}$ \\
\hline Temperature Coefficient of $I_{S C}$ & 0.065 \\
\hline Reference solar intensity & $1000 \mathrm{~W} / \mathrm{m}^{2}$ \\
\hline Coupling inductance $L$ & $1.35 \mathrm{mH}$ \\
\hline DC link capacitor $C_{D C}$ & $80 \mathrm{mF}$ \\
\hline$C_{I}$ & $10 \mathrm{mF}$ \\
\hline$L_{I}$ & $5 \mathrm{mH}$ \\
\hline Converter switching frequency & $5 \mathrm{kHz}$ \\
\hline
\end{tabular}

\section{Acknowledgment}

The authors acknowledge the support provided by the Deanship of Scientific Research, King Fahd University of Petroleum \& Minerals, through Electrical Power and Energy Systems Research Group funded project \# RG1420-1\&2.

\section{References}

[1] Trends in Photovoltaic Applications. Survey report of selected IEA countries between 1992 and 2007," Available online at: http://www.iea-pvps.org. Retrieved February 2009.

[2] T. Esram, P.L. Chapman, "Comparison of Photovoltaic Array Maximum Power Point Tracking Techniques," IEEE Transaction on Energy Conversion, June 2007, vol.22, no.2, pp.439-449.

[3] B. Subudhi and R. Pradhan, "A Comparative Study on Maximum Power Point Tracking Techniques for Photovoltaic Power Systems," IEEE Transactions on Sustainable Energy, Jan. 2013, vol. 4, no. 1, pp. 89-98.

[4] Muhammed. Y. Worku and M. A. Abido, "Real-time implementation of grid-connected PV system with decoupled P-Q controllers," 2014 22nd Mediterranean Conference of Control and Automation (MED), Palermo, Italy, June 16-19, 2014, pp. $841-846$.

[5] B. N. Alajmi, K. H. Ahmed, S. J. Finney, and B. W. Williams, "Fuzzy logic- control approach of a modified hillclimbing method for maximum power point in microgrid standalone photovoltaic system," IEEE Trans. Power Electron., Apr. 2011,vol. 26, no. 4, pp. 1022-1030.

[6] A. K. Rai, N. D. Kaushika, B. Singh, and N. Agarwal, "Simulation model of ANN based maximum power point tracking controller for solar PV system," Solar Energy Mater. Solar Cells, 2011,vol. 95, pp. 773-778.

[7] M. Tsai, C. Tseng, G. Hong, and S. Lin, "A novel MPPT control design for PV modules using neural network compensator," in 2012 IEEE International Symposium on Industrial Electronics, pp. 1742-1747.

[8] N. Patcharaprakiti and S. Premrudeepreechacharn, "Maximum power point tracking using adaptive fuzzy logic control for grid-connected photovoltaic system," in 2002 IEEE Power Engineering Society Winter Meeting. Conference Proceedings (Cat. No.02CH37309), vol. 1, pp. 372-377.

[9] B. N. Alajmi, K. H. Ahmed, S. J. Finney, and B. W. Williams, "A Maximum Power Point Tracking Technique for Partially Shaded Photovoltaic Systems in Microgrids," IEEE Transactions on Industrial Electronics, Apr. 2013, vol. 60 , no. 4, pp. 1596-1606.

[10] T. L. Kottas, Y. S. Boutalis, and A. D. Karlis, "New Maximum Power Point Tracker for PV Arrays Using Fuzzy Controller in Close Cooperation With Fuzzy Cognitive Networks," IEEE Transactions on Energy Conversion, Sep. 2006, vol. 21, no. 3, pp. 793-803.

[11] J.-S. R. Jang, "ANFIS: adaptive-network-based fuzzy inference system," IEEE Transactions on Systems, Man, and Cybernetics, 1993, vol. 23, no. 3, pp. 665-685.

[12] J.-S. R. Jang, "Neuro-fuzzy modeling and control," Proceedings of the IEEE, Mar. 1995, vol. 83, no. 3, pp. 378-406.

[13] A. M. S. Aldobhani and R. John, "Maximum Power Point Tracking of PV System Using ANFIS Prediction and Fuzzy Logic Tracking," in International MultiConference of Engineers and Computer Scientists (IMECS), 2008, vol. II, pp. 19-21.

[14] F. Mayssa and L. Sbita, "Advanced ANFIS-MPPT control algorithm for sunshine photovoltaic pumping systems," First International Conf. on Renewable Energies and Vehicular Technology, 2012, pp. 167-172.

[15] H. Abu-Rub, A. Iqbal, S. Moin Ahmed, F. Z. Peng, Y. Li, and G. Baoming, "Quasi-Z-Source Inverter-Based Photovoltaic Generation System With Maximum Power Tracking Control Using ANFIS," IEEE Trans. on Sustainable Energy, Jan. 2013, vol. 4, no. 1, pp. 11-20.

[16] M. A. Abido, M. Sheraz Khalid, Muhammed Y. Worku, "An Efficient ANFIS-Based PI Controller for Maximum Power Point Tracking of PV Systems", Arab J Sci Eng (2015) Vol. 40 pp. 2641-2651.

[17] A.V. Timbus, T. Teodorescu, F. Blaabjerg, M. Liserre, P. Rodriguez, PLL Algorithm for Power Generation Systems Robust to Grid Voltage Faults," 37th IEEE on Power Electronics Specialists Conf., 2006. 